\title{
WHEN IS AN INVARIANT MEAN THE LIMIT OF A FØLNER NET?
}

\author{
JOHN HOPFENSPERGER
}

\begin{abstract}
Let $\mathrm{G}$ be a locally compact amenable group, TLIM $(\mathrm{G})$ the topological left-invariant means on $\mathrm{G}$, and $\operatorname{TLIM}_{0}(\mathrm{G})$ the limit points of Følner-nets. I show that $\operatorname{TLIM}_{0}(\mathrm{G})=\operatorname{TLIM}(\mathrm{G})$ unless $\mathrm{G}$ is $\sigma$-compact non-unimodular, in which case $\operatorname{TLIM}_{0}(\mathrm{G}) \neq \operatorname{TLIM}(\mathrm{G})$. This improves a 1970 result of Chou and a 2009 result of Hindman and Strauss. I consider the analogous problem for the non-topological left-invariant means, and give a short construction of a net converging to invariance "weakly but not strongly," simplifying the proof of a 2001 result of Rosenblatt and Willis.
\end{abstract}

\section{History}

In this paper, $\mathrm{G}$ is always a locally compact group. The left Haar measure of $\mathrm{E} \subset \mathrm{G}$ is denoted $|\mathrm{E}|$. The set of means on $\mathcal{L}_{\infty}(\mathrm{G})$ is $\mathcal{M}(\mathrm{G})=\left\{\mu \in \mathcal{L}_{\infty}^{*}(\mathrm{G}):\|\mu\|=1, \mu \geq 0\right\}$, which is endowed with the $w^{*}$-topology to make it compact. Regarding $\mathcal{L}_{1}(\mathrm{G})$ as a subset of $\mathcal{L}_{\infty}^{*}(\mathrm{G})$, define $\mathcal{M}_{1}(\mathrm{G})=\left\{f \in \mathcal{L}_{1}(\mathrm{G}):\|f\|_{1}=1, f \geq 0\right\}$.

Proposition 1.1 ([Gre69, page 1]). $\mathcal{M}_{1}(\mathrm{G})$ is dense in $\mathcal{M}(\mathrm{G})$.

Define left-translation of functions by $l_{x} \phi(y)=\phi\left(x^{-1} y\right)$. The set of left-invariant means on $\mathcal{L}_{\infty}(\mathrm{G})$ is

$$
\operatorname{LIM}(\mathrm{G})=\left\{\mu \in \mathcal{M}(\mathrm{G}):(\forall x \in \mathrm{G})\left(\forall \phi \in \mathcal{L}_{\infty}(\mathrm{G})\right) \mu(\phi)=\mu\left(l_{x} \phi\right)\right\} .
$$

$\mathrm{G}$ is said to be amenable if $\operatorname{LIM}(\mathrm{G})$ is nonempty. Proposition 1.1 shows that every left-invariant mean $\mu$ is the limit of a net $\left\langle f_{\alpha}\right\rangle$ in $\mathcal{M}_{1}(\mathrm{G})$. Such a net is said to converge weakly to invariance, because the net $\left\langle f_{\alpha}-l_{x} f_{\alpha}\right\rangle$ converges weakly to 0 for all $x \in \mathrm{G}$.

A mean $f \in \mathcal{M}_{1}(\mathrm{G})$ is said to be $(\mathrm{K}, \epsilon)$-invariant if $\left\|f-l_{x} f\right\|_{1}<\epsilon$ for each $x \in \mathrm{K}$. A net in $\mathcal{M}_{1}(\mathrm{G})$ is said to converge strongly to invariance if it is eventually $(\mathrm{K}, \epsilon)$-invariant for each finite $\mathrm{K} \subset \mathrm{G}$ and $\epsilon>0$.

Proposition 1.2 ([Gre69, Theorem 2.4.2]). If $\mathrm{G}$ is amenable, $\mathcal{M}_{1}(\mathrm{G})$ contains a net converging strongly to invariance.

Let $\mathscr{C}^{+}$be the compact subsets of $\mathrm{G}$ with positive measure. For $\mathrm{A} \in \mathscr{C}^{+}$define $\mu_{\mathrm{A}}=\chi_{\mathrm{A}} /|\mathrm{A}| \in \mathcal{M}_{1}(\mathrm{G})$. If $\mu_{\mathrm{A}}$ is $(\mathrm{K}, \epsilon)$-invariant, we may also say $\mathrm{A}$ is $(\mathrm{K}, \epsilon)$-invariant. Notice $\left\|\mu_{\mathrm{A}}-l_{x} \mu_{\mathrm{A}}\right\|_{1}=|\mathrm{A} \triangle x \mathrm{~A}| /|\mathrm{A}|$. Let $\mathcal{M}_{\mathscr{C}^{+}}(\mathrm{G})=\left\{\mu_{\mathrm{A}}: \mathrm{A} \in \mathscr{C}^{+}\right\}$.

Proposition 1.3 ([Gre69, Theorem 3.6.1]). If $\mathrm{G}$ is amenable, $\mathcal{M}_{\mathscr{C}^{+}}(\mathrm{G})$ contains a net $\left\langle\mu_{\mathrm{A}_{\alpha}}\right\rangle$ converging strongly to invariance. In this case, both $\left\langle\mu_{\mathrm{A}_{\alpha}}\right\rangle$ and $\left\langle\mathrm{A}_{\alpha}\right\rangle$ are called Følner nets.

Question 1.4. Is it possible to construct a net converging weakly but not strongly to invariance?

The main result of [RW01] is that every $\mu \in \operatorname{LIM}(\mathrm{G})$ is the limit of some net in $\mathcal{M}_{1}(\mathrm{G})$ not converging strongly to invariance. Theorems 2.3 and 2.6 give a shorter proof of a slightly stronger result: Every non-atomic $\mu \in \mathcal{M}(\mathrm{G})$ is the limit of some net in $\mathcal{M}_{\mathscr{C}^{+}}(\mathrm{G})$ not converging strongly to invariance.

Question 1.5. Let $\operatorname{LIM}_{0}(\mathrm{G})$ be the limit points of Følner nets. Does $\operatorname{LIM}_{0}(\mathrm{G})=\mathrm{LIM}(\mathrm{G})$ ?

Hindman and Strauss asked this question for amenable semigroups in [HS09], and answered it affirmatively for the semigroup $(\mathbb{N},+)$. The following theorems extend their affirmative result: Theorem 5.9 when $\mathrm{G}$ is discrete, Theorem 7.2 when $\mathrm{G}$ is larger than $\sigma$-compact, and Theorem 7.4 when $\mathrm{G}$ is non-discrete but amenable-as-discrete. The question remains open when $\mathrm{G}$ is compact or $\sigma$-compact but not amenable-as-discrete.

For $f \in \mathcal{M}_{1}(\mathrm{G})$, regard $f * \phi$ as the average $\int_{\mathrm{G}} f(x) l_{x} \phi \mathrm{d} x$ of left-translates of $\phi$. The set of topological left-invariant means on $\mathcal{L}_{\infty}(\mathrm{G})$ is

$$
\operatorname{TLIM}(\mathrm{G})=\left\{\mu \in \mathcal{M}(\mathrm{G}):\left(\forall f \in \mathcal{M}_{1}(\mathrm{G})\right)\left(\forall \phi \in \mathcal{L}_{\infty}(\mathrm{G})\right) \mu(\phi)=\mu(f * \phi)\right\} .
$$


Proposition 1.6. When $G$ is discrete, $\operatorname{LIM}(G)=\operatorname{TLIM}(G)$.

Proof. When $\mathrm{G}$ is discrete, every $f \in \mathcal{M}_{1}(\mathrm{G})$ is a sum of point-masses. Convolution by a point-mass is equivalent to left-translation.

A net in $\mathcal{M}_{1}(\mathrm{G})$ is said to converge strongly to topological invariance if it is eventually $(\mathrm{K}, \epsilon)$-invariant for each compact $\mathrm{K} \subset \mathrm{G}$ and $\epsilon>0$.

Proposition 1.7 ([Gre69, Corollary 2.4.4]). If $\left\langle f_{\alpha}\right\rangle$ is a net in $\mathcal{M}_{1}(\mathrm{G})$ converging strongly to topological invariance, and $f_{\alpha} \rightarrow \mu$, then $\mu \in \operatorname{TLIM}(\mathrm{G})$.

Proposition 1.8 ([Gre69, Proposition 3.6.2]). If $\mathrm{G}$ is amenable, $\mathcal{M}_{\mathscr{C}^{+}}(\mathrm{G})$ contains a net $\left\langle\mu_{\mathrm{A}_{\alpha}}\right\rangle$ converging strongly to topological invariance. In this case, both $\left\langle\mu_{\mathrm{A}_{\alpha}}\right\rangle$ and $\left\langle\mathrm{A}_{\alpha}\right\rangle$ are called topological Følner nets.

For example, $\langle[-n, n]\rangle_{n=1}^{\infty}$ is a topological Følner sequence for $\mathbb{R}$. By [Eme68, Theorem 3], there is no such thing as a non-topological Følner sequence.

Question 1.9. If $\mathrm{G}$ is amenable and non-discrete, is it possible to construct a non-topological Følner net?

When $\mathrm{G}$ is amenable-as-discrete, there exists $\mu \in \mathrm{LIM}(\mathrm{G}) \backslash \mathrm{TLIM}(\mathrm{G}), c f$. [Ros76]. In this case, Theorem 7.4 yields a net $\left\langle\mu_{X_{\alpha} S_{\alpha}}\right\rangle$ converging to $\mu$, which is clearly a non-topological Følner net. Otherwise the question remains open.

Question 1.10. Let $\operatorname{TLIM}_{0}(\mathrm{G})$ be the limit points of topological Følner nets. Does $\operatorname{TLIM}_{0}(\mathrm{G})=\mathrm{TLIM}(\mathrm{G})$ ?

A partial answer was given by Chou, who showed in [Cho70] that TLIM(G) is the closed convex hull of $\operatorname{TLIM}_{0}(\mathrm{G})$. The main result of the present paper is to answer this question completely. If $\mathrm{G}$ is $\sigma$-compact nonunimodular, the answer is negative by Theorem 6.2. In all other cases the answer is affirmative: by Proposition 3.2 when $\mathrm{G}$ is compact, by Theorem 5.9 when $\mathrm{G}$ is unimodular, and by Theorem 6.1 when $\mathrm{G}$ is larger than $\sigma$-compact.

\section{Converging to INVARIANCE WEAKLy BUt NOT STRONGLY}

A neighborhood basis about $\mu \in \mathcal{M}(\mathrm{G})$ is given by sets of the form

$$
\mathcal{N}(\mu, \mathcal{F}, \epsilon)=\{v \in \mathcal{M}(\mathrm{G}):(\forall f \in \mathcal{F})|\mu(f)-v(f)|<\epsilon\}
$$

where $\mathcal{F}$ ranges over finite subsets of $\mathcal{L}_{\infty}(\mathrm{G})$ and $\epsilon$ ranges over $(0,1)$.

Lemma 2.1. Regard each $\mu \in \mathcal{M}$ as a finitely additive measure via $\mu(E)=\mu\left(\chi_{E}\right)$. Then a neighborhood basis about $\mu \in \mathcal{M}$ is given by sets of the form

$$
\mathcal{N}(\mu, \mathcal{P}, \epsilon)=\{v \in \mathcal{M}:(\forall \mathrm{E} \in \mathcal{P})|\mu(\mathrm{E})-v(\mathrm{E})|<\epsilon\}
$$

where $\epsilon$ ranges over $(0,1)$ and $\mathcal{P}$ ranges over finite measurable partitions of $\mathrm{G}$.

Proof. Pick $\mathcal{N}(\mu, \mathcal{F}, \epsilon)$. For simplicity, suppose $\mathcal{F}$ consists of simple functions. Let $\mathrm{M}=\max \left\{\|f\|_{\infty}: f \in \mathcal{F}\right\}$. Let $\mathcal{P}$ be the atoms of the measure algebra generated by $\mathcal{F}$. Then $\mathcal{N}\left(\mu, \mathcal{P}, \frac{\epsilon}{\# \cdot \mathcal{M}}\right) \subset \mathcal{N}(\mu, \mathcal{F}, \epsilon)$.

Lemma 2.2. Let $\mathrm{E} \subset \mathrm{G}$ be any infinite subset, $n \in \mathbb{N}$, and $x \in \mathrm{G} \backslash\{e\}$. Then there exists $\mathrm{S} \subset \mathrm{E}$ with $\# \mathrm{~S}=n$ and $\mathrm{S} \cap x \mathrm{~S}=\varnothing$.

Proof. If $n=0$, take $\mathrm{S}=\varnothing$. Inductively, suppose there exists $\mathrm{R} \subset \mathrm{E}$ with $\# \mathrm{R}=n-1$ and $\mathrm{R} \cap x \mathrm{R}=\varnothing$. Pick any $y \in \mathrm{E} \backslash\left\{x, x^{-1}\right\} \mathrm{R}$, and let $\mathrm{S}=\mathrm{R} \cup\{y\}$.

Theorem 2.3. Suppose $\mathrm{G}$ is discrete, $\mu \in \mathcal{M}$ vanishes on finite sets, and $x \in \mathrm{G} \backslash\{e\}$. Then there exists a net $\left\langle\mathrm{S}_{\mathcal{P}}\right\rangle$ in $\mathscr{C}^{+}$so $\mu_{\mathrm{S}_{\mathcal{P}}} \rightarrow \mu$, but $\mathrm{S}_{\mathcal{P}} \cap x \mathrm{~S}_{\mathcal{P}}=\varnothing$ for all $\mathcal{P}$.

Proof. Let $\mathscr{P}$ be the directed set of all finite partitions of $\mathrm{G}$, ordered by refinement. Pick $\mathcal{P}=\left\{\mathrm{E}_{1}, \ldots, \mathrm{E}_{p}\right\} \in \mathscr{P}$. For $1 \leq i \leq p$, we will choose $\mathrm{S}_{i} \subset \mathrm{E}_{i}$ such that $\left|\frac{\# \mathrm{~S}_{i}}{\# \mathrm{~S}_{1}+\ldots+\# \mathrm{~S}_{p}}-\mu\left(\mathrm{E}_{i}\right)\right|<\frac{1}{p}$, and take $\mathrm{S}_{\mathcal{P}}=\mathrm{S}_{1} \cup \ldots \cup \mathrm{S}_{p}$. Then $\left|\mu_{\mathrm{S}_{\mathcal{P}}}\left(\mathrm{E}_{i}\right)-\mu\left(\mathrm{E}_{i}\right)\right|<\frac{1}{p}$, and $\mu_{\mathrm{S}_{\mathcal{P}}} \rightarrow \mu$ by Lemma 2.1 .

We begin by establishing the values $n_{i}=\# \mathrm{~S}_{i}$. If $\mu\left(\mathrm{E}_{i}\right)=0$, let $n_{i}=0$. Otherwise $\mu\left(\mathrm{E}_{i}\right)>0$, hence $\mathrm{E}_{i}$ is infinite. In this case, let $n_{i} \geq 0$ be an integer such that $\left|\frac{n_{i}}{2 p^{2}}-\mu\left(\mathrm{E}_{i}\right)\right|<\frac{1}{2 p^{2}}$. Let $\mathrm{N}=\sum_{i=1}^{p} n_{i}$. Now $\left|\frac{n_{i}}{2 p^{2}}-\frac{n_{i}}{\mathrm{~N}}\right|=\frac{n_{i}}{\mathrm{~N}} \cdot\left|\frac{\mathrm{N}}{2 p^{2}}-1\right| \leq\left|\frac{\mathrm{N}}{2 p^{2}}-1\right|=\left|\sum_{i} \frac{n_{i}}{2 p^{2}}-\mu\left(\mathrm{E}_{i}\right)\right|<\frac{1}{2 p}$, so $\left|\mu\left(\mathrm{E}_{i}\right)-\frac{n_{i}}{\mathrm{~N}}\right|<\frac{1}{p}$. 
Apply Lemma 2.2 to choose $\mathrm{S}_{1} \subset \mathrm{E}_{1}$ with $\mathrm{S}_{1} \cap x \mathrm{~S}_{1}=\varnothing$. For $k<p$, inductively choose $\mathrm{S}_{k+1} \subset \mathrm{E}_{k+1} \backslash$ $\left\{x, x^{-1}\right\}\left(\mathrm{S}_{1} \cup \ldots \cup \mathrm{S}_{k}\right)$ with $\# \mathrm{~S}_{k+1}=n_{k}$ and $\mathrm{S}_{k+1} \cap x \mathrm{~S}_{k+1}=\varnothing$. Let $\mathrm{S}_{\mathcal{P}}=\mathrm{S}_{1} \cup \ldots \cup \mathrm{S}_{p}$. Now $\mu_{\mathrm{S}_{\mathcal{P}}}\left(\mathrm{E}_{i}\right)=\frac{n_{i}}{\mathrm{~N}}$ and $\mathrm{S}_{\mathcal{P}} \cap x \mathrm{~S}_{\mathcal{P}}=\varnothing$, as desired.

2.4. The hypothesis " $\mu$ vanishes on finite sets" is necessary in Theorem 2.3 . For example, pick $x, y \in \mathrm{G}$ and define $\mu \in \mathcal{M}$ by $\mu(\{x\})=\frac{2}{3}$ and $\mu(\{y\})=\frac{1}{3}$. For each $\mathrm{F} \in \mathscr{C}^{+}, \mu_{\mathrm{F}}(\{x\}) \in\left\{1, \frac{1}{2}, \frac{1}{3}, \ldots\right\}$, hence $\left|\mu(\{x\})-\mu_{\mathrm{F}}(\{x\})\right| \geq \frac{1}{6}$. This foreshadows Theorem 6.2.

Lemma 2.5. Suppose $\mathrm{G}$ is not discrete. Pick $\mathrm{E} \subset \mathrm{G}$ with positive measure, and $\mathrm{X}=\left\{x_{1}, \ldots, x_{n}\right\} \subset \mathrm{G}$. For any $c>0$, there exists $\mathrm{S} \subset \mathrm{E}$ such that $0<|\mathrm{S}| \leq c$ and $\left\{x_{1} \mathrm{~S}, \ldots, x_{n} \mathrm{~S}\right\}$ are mutually disjoint.

Proof. Let $\mathrm{K} \subset \mathrm{E}$ be any compact set with positive measure. Let $\mathrm{U}$ be a small neighborhood of $e$, so $\mathrm{UU}^{-1} \cap \mathrm{X}^{-1} \mathrm{X}=$ $\{e\}$ and $\max _{k \in \mathrm{K}}|\mathrm{U} k| \leq c$. Pick $k_{1}, \ldots, k_{n} \in \mathrm{K}$ such that $\mathrm{K} \subset \mathrm{U} k_{1} \cup \ldots \cup \mathrm{U} k_{n}$. Now $0<|\mathrm{K}| \leq \sum_{i=1}^{n}\left|\mathrm{U} k_{i} \cap \mathrm{K}\right|$, hence $0<\left|\mathrm{U} k_{i} \cap \mathrm{K}\right|$ for some $i$. Take $\mathrm{S}=\mathrm{U} k_{i} \cap \mathrm{K}$.

Theorem 2.6. Suppose $\mathrm{G}$ is not discrete. Given any $\mu \in \mathcal{M}$ and $x \in \mathrm{G} \backslash\{e\}$, there exists a net $\left\langle\mathrm{S}_{\mathcal{P}}\right\rangle$ in $\mathscr{C}^{+}$so that $\mu_{\mathrm{S}_{\mathcal{P}}} \rightarrow \mu$, but $\mathrm{S}_{\mathcal{P}} \cap x \mathrm{~S}_{\mathcal{P}}=\varnothing$ for all $\mathcal{P}$.

Proof. The following construction yields sets $\left\langle\mathrm{S}_{\mathcal{P}}\right\rangle$ that may not be compact. This suffices to prove the theorem, since each $\mathrm{S}_{\mathcal{P}}$ can be approximated from within by a compact set.

Let $\mathscr{P}$ be the directed set of all finite measurable partitions of $\mathrm{G}$, ordered by refinement. Pick $\mathscr{P}=\left\{\mathrm{E}_{1}, \ldots, \mathrm{E}_{p}\right\} \in$ $\mathscr{P}$. For $1 \leq i \leq p$, we will choose $\mathrm{S}_{i}^{\prime} \subset \mathrm{E}_{i}$ such that $\left|\mathrm{S}_{i}^{\prime}\right| /\left(\left|\mathrm{S}_{1}^{\prime}\right|+\ldots+\left|\mathrm{S}_{k}^{\prime}\right|\right)=\mu\left(\mathrm{E}_{i}\right)$, then take $\mathrm{S}_{\mathcal{P}}=\mathrm{S}_{1}^{\prime} \cup \ldots \cup \mathrm{S}_{p}^{\prime}$. Thus $\mu_{\mathrm{S}_{\mathcal{P}}}\left(\mathrm{E}_{i}\right)=\mu\left(\mathrm{E}_{i}\right)$, and $\mu_{\mathrm{S}_{\mathcal{P}}} \rightarrow \mu$ by Lemma 2.1 .

If $\mu\left(\mathrm{E}_{i}\right)=0$ we can take $\mathrm{S}_{i}=\varnothing$, so assume $0<m=\min \left\{1,\left|\mathrm{E}_{1}\right|, \ldots,\left|\mathrm{E}_{p}\right|\right\}$ and let $c=m / 2 p$. By Lemma 2.5, choose $\mathrm{S}_{1} \subset \mathrm{E}_{1}$ with $0<\left|\mathrm{S}_{1}\right| \leq c$ and $\mathrm{S}_{1} \cap x \mathrm{~S}_{1}=\varnothing$. For $k<p$, inductively choose $\mathrm{S}_{k+1} \subset \mathrm{E}_{k+1} \backslash\left\{x, x^{-1}\right\}\left(\mathrm{S}_{1} \cup \ldots \cup\right.$ $\mathrm{S}_{k}$ ) with $0<\left|\mathrm{S}_{k+1}\right| \leq c$ and $\mathrm{S}_{k+1} \cap x \mathrm{~S}_{k+1}=\varnothing$. This is possible, since $\left|\mathrm{E}_{k+1} \backslash\left\{x, x^{-1}\right\}\left(\mathrm{S}_{1} \cup \ldots \cup \mathrm{S}_{k}\right)\right| \geq m-2 k c>0$.

Finally, let $m^{\prime}=\min \left\{\left|\mathrm{S}_{1}\right|,\left|\mathrm{S}_{2}\right|, \ldots,\left|\mathrm{S}_{p}\right|\right\}$. For each $i$, choose $\mathrm{S}_{i}^{\prime} \subset \mathrm{S}_{i}$ with $\left|\mathrm{S}_{i}^{\prime}\right|=m^{\prime} \cdot \mu\left(\mathrm{E}_{i}\right)$. Now $\mu_{\mathrm{S}_{\mathcal{P}}}\left(\mathrm{E}_{i}\right)=\mu\left(\mathrm{E}_{i}\right)$ and $\mathrm{S}_{\mathcal{P}} \cap x \mathrm{~S}_{\mathcal{P}}=\varnothing$, as desired.

\section{3. $\kappa$-COMPACTNESS}

Definition 3.1. For the rest of the paper, triples of the form $(\mathcal{P}, \mathrm{K}, \epsilon)$ are always understood to range over finite measurable partitions $\mathcal{P}$ of $\mathrm{G}$, compact sets $\mathrm{K} \subset \mathrm{G}$, and $\epsilon \in(0,1)$. Recall that $\mathscr{C}^{+}(\mathrm{K}, \epsilon)$ is the set of all compact $(\mathrm{K}, \epsilon)$-invariant sets with positive measure. In these terms, we can give the formal definition:

$$
\operatorname{TLIM}_{0}(\mathrm{G})=\left\{\mu \in \operatorname{TLIM}(\mathrm{G}):(\forall(\mathcal{P}, \mathrm{K}, \epsilon))\left(\exists \mathrm{A} \in \mathscr{C}^{+}(\mathrm{K}, \epsilon)\right) \mu_{\mathrm{A}} \in \mathcal{N}(\mu, \mathcal{P}, \epsilon)\right\} .
$$

For $\mathrm{S} \subset \mathrm{G}$, let $\kappa(\mathrm{S})$ denote the smallest cardinal such that there exists $\mathcal{K}$, a collection of compact subsets of $\mathrm{G}$ with $\# \mathcal{K}=\kappa(S)$ and $S \subset \cup \mathcal{K}$. Notice that either $\kappa(G)=1, \kappa(G)=\mathbb{N}$, or $\kappa(G)>\mathbb{N}$.

Proposition 3.2. When $\kappa(\mathrm{G})=1$, $\operatorname{TLIM}_{0}(\mathrm{G})=\operatorname{TLIM}(\mathrm{G})=\left\{\mu_{\mathrm{G}}\right\}$.

Proof. Pick $\mu \in \operatorname{TLIM}(\mathrm{G})$. Since $\mathrm{G}$ is compact, $\chi_{\mathrm{G}} \in \mathrm{C}_{0}(\mathrm{G})$ and $\mu_{\mathrm{G}}\left(\chi_{\mathrm{G}}\right)=1$. Thus $\left.\mu\right|_{\mathrm{C}_{0}(\mathrm{G})}$ is nonzero, and it induces a nonzero left-invariant measure on $\mathrm{G}$ via the Riesz-Kakutani representation theorem. By the uniqueness of Haar measure, we see $\left.\mu\right|_{\mathrm{C}_{0}(\mathrm{G})}=\left.\mu_{\mathrm{G}}\right|_{\mathrm{C}_{0}(\mathrm{G})}$. Pick $\phi \in \mathcal{L}_{\infty}(\mathrm{G})$ and $f \in \mathrm{P}_{1}(\mathrm{G})$. Then $f * \phi \in \mathrm{C}_{0}(\mathrm{G})$, so $\mu(\phi)=\mu(f * \phi)=\mu_{\mathrm{G}}(f * \phi)=\mu_{\mathrm{G}}(\phi)$.

Lemma 3.3. If $\mu \in \operatorname{LIM}(\mathrm{G})$ and $\kappa(\mathrm{S})<\kappa(\mathrm{G})$, then $\mu(\mathrm{S})=0$.

Proof. Since $\mathbb{N} \cdot \kappa(\mathrm{S}) \leq \kappa(\mathrm{G})$, we can find disjoint translates $\left\{x_{1} \mathrm{~S}, x_{2} \mathrm{~S}, \ldots\right\}$. If $\mu(\mathrm{S})>0$, then $\mu\left(x_{1} \mathrm{~S} \cup \ldots \cup x_{n} \mathrm{~S}\right)=$ $n \cdot \mu(\mathrm{S})$ is eventually greater than 1 , contradicting $\|\mu\|=1$.

3.4. Throughout the paper, we make free use of the following formulas:

For $\mathrm{A}, \mathrm{B} \in \mathscr{C}^{+},\left\|\mu_{\mathrm{A}}-\mu_{\mathrm{B}}\right\|_{1}=\frac{|\mathrm{A} \backslash \mathrm{B}|}{|\mathrm{A}|}+\frac{|\mathrm{B} \backslash \mathrm{A}|}{|\mathrm{B}|}+|\mathrm{A} \cap \mathrm{B}| \cdot\left|\frac{1}{|\mathrm{~A}|}-\frac{1}{|\mathrm{~B}|}\right|$.

If $\mathrm{A} \subset \mathrm{B}$, this becomes $\left\|\mu_{\mathrm{A}}-\mu_{\mathrm{B}}\right\|_{1}=0+\frac{|\mathrm{B} \backslash \mathrm{A}|}{|\mathrm{B}|}+|\mathrm{A}|\left(\frac{1}{|\mathrm{~A}|}-\frac{1}{|\mathrm{~B}|}\right)=2 \frac{|\mathrm{B} \backslash \mathrm{A}|}{|\mathrm{B}|}$.

Lemma 3.5. Pick $(\mathcal{P}, \mathrm{K}, \epsilon)$ and $\mu \in \operatorname{TLIM}_{0}(\mathrm{G})$. Let $\kappa=\kappa(\mathrm{G})$. There exists a family of mutually disjoint sets $\left\{\mathrm{A}_{\alpha}: \alpha<\kappa\right\} \subset \mathscr{C}^{+}(\mathrm{K}, \epsilon)$ such that $\left\{\mu_{\mathrm{A}_{\alpha}}: \alpha<\kappa\right\} \subset \mathcal{N}(\mu, \mathcal{P}, \epsilon)$. 
Proof. Choose any precompact open set U. For $\beta<\kappa(\mathrm{G})$, suppose $\left\{\mathrm{A}_{\alpha}: \alpha<\beta\right\} \subset \mathscr{C}^{+}(\mathrm{K}, \epsilon)$ have been chosen so that $\left\{\mathrm{A}_{\alpha} \mathrm{U}: \alpha<\beta\right\}$ are mutually disjoint and $\left\{\mu_{\mathrm{A}_{\alpha}}: \alpha<\beta\right\} \subset \mathcal{N}(\mu, \mathcal{P}, \epsilon)$. Once $\mathrm{A}_{\beta}$ is constructed, the result follows by transfinite induction.

Define $\mathrm{B}=\bigcup_{\alpha<\beta} \mathrm{A}_{\alpha} \mathrm{UU}^{-1}$, which is open and thus measurable. Notice $\kappa(\mathrm{B})=\beta<\kappa(\mathrm{G})$. If $\mathcal{P}=\left\{\mathrm{E}_{1}, \ldots, \mathrm{E}_{p}\right\}$, let $\mathcal{P}_{\mathrm{B}}=\left(\mathrm{E}_{1} \backslash \mathrm{B}, \ldots, \mathrm{E}_{p} \backslash \mathrm{B}, \mathrm{B}\right)$. Let $\delta=\epsilon / 4$, and pick $\mathrm{A} \in \mathscr{C}^{+}(\mathrm{K}, \delta)$ with $\mu_{\mathrm{A}} \in \mathcal{N}\left(\mu, \mathcal{P}_{\mathrm{B}}, \delta\right)$. Define $\mathrm{A}_{\beta}=\mathrm{A} \backslash \mathrm{B}$, which ensures $\left\{\mathrm{A}_{\alpha} \mathrm{U}: \alpha \leq \beta\right\}$ are mutually disjoint. Lemma 3.3 tells us $\mu(\mathrm{B})=0$, hence $\mu_{\mathrm{A}}(\mathrm{B})<\delta$. Thus $\left\|\mu_{\mathrm{A}}-\mu_{\mathrm{A}_{\beta}}\right\|_{1}=2 \frac{\left|\mathrm{A} \backslash \mathrm{A}_{\beta}\right|}{|\mathrm{A}|}=2 \frac{|\mathrm{A} \cap \mathrm{B}|}{|\mathrm{A}|}=2 \mu_{\mathrm{A}}(\mathrm{B})<2 \delta$. By the triangle inequality, $\mu_{\mathrm{A}_{\beta}} \in \mathcal{N}(\mu, \mathcal{P}, 3 \delta)$. If $x \in \mathrm{K}$, $\left|x \mathrm{~A}_{\beta} \triangle \mathrm{A}_{\beta}\right| \leq\left|x \mathrm{~A}_{\beta} \triangle x \mathrm{~A}\right|+|x \mathrm{~A} \triangle \mathrm{A}|+\left|\mathrm{A} \triangle \mathrm{A}_{\beta}\right|<3 \delta|\mathrm{A}|<4 \delta\left|\mathrm{A}_{\beta}\right|$, so $\mathrm{A}_{\beta} \in \mathscr{C}^{+}(\mathrm{K}, 4 \delta)$.

\section{The method of Hindman and Strauss}

Lemma 4.1. The closed convex hull of $\operatorname{TLIM}_{0}(\mathrm{G})$ is all of TLIM $(\mathrm{G})$.

Proof. Chou originally proved this for $\sigma$-compact groups, see [Cho70, Theorem 3.2]. In [Mil81], Milnes points out that the result is valid even when $\mathrm{G}$ is not $\sigma$-compact, although his construction of a Følner-net $\left\langle\mathrm{U}_{\alpha}\right\rangle$ has a small problem: For each index $\alpha$, he asks us to choose a compact set $\mathrm{U}_{\alpha}$, such that $\mathrm{U}_{\beta} \subset \mathrm{U}_{\alpha}$ for $\beta<\alpha$. However, $\alpha$ may have infinitely many predecessors, in which case $\bigcup_{\beta<\alpha} U_{\beta}$ has no reason to be precompact! For a correct proof in full generality, see [Hop20, Lemma 4.11].

The following deceptively simple lemma is due to Hindman and Strauss, see [HS09, Proof of Theorem 4.5].

Lemma 4.2. Suppose $\left[\mu, v \in \operatorname{TLIM}_{0}(G)\right] \Rightarrow\left[\frac{1}{2}(\mu+v) \in \operatorname{TLIM}_{0}(G)\right]$. Then $\operatorname{TLIM}_{0}(G)=\operatorname{TLIM}(G)$.

Proof. Since the dyadic rationals are dense in $[0,1]$ and $\operatorname{TLIM}_{0}(\mathrm{G})$ is closed, the hypothesis implies $\mathrm{TLIM}_{0}(\mathrm{G})$ is convex. The result follows by Lemma 4.1.

Lemma 4.2 is useful because $\frac{1}{2}\left(\mu_{\mathrm{A}}+\mu_{\mathrm{B}}\right)=\mu_{\mathrm{A} \cup \mathrm{B}}$ when $\mathrm{A}, \mathrm{B} \in \mathscr{C}^{+}$are disjoint and equal in measure. Lemma 4.3 tells us what happens when $\mathrm{A}$ and $\mathrm{B}$ are approximately disjoint and equal in measure.

Lemma 4.3. Pick $A, B \in \mathscr{C}^{+}$and $\delta \in\left(0, \frac{1}{2}\right)$. Suppose $\mu_{B}(A)<\delta$ and $|A| /|B| \in\left((1-\delta)^{2},(1+\delta)^{2}\right)$. Then $\left\|\mu_{\mathrm{A} \cup \mathrm{B}}-\frac{1}{2}\left(\mu_{\mathrm{A}}+\mu_{\mathrm{B}}\right)\right\|_{1}<3 \delta$.

Proof. Let $\mathrm{B}^{\prime}=\mathrm{B} \backslash \mathrm{A}$ and $r=\frac{|\mathrm{A}|}{\left|\mathrm{B}^{\prime}\right|}=\frac{|\mathrm{A}|}{|\mathrm{B}|} \cdot \frac{|\mathrm{B}|}{\left|\mathrm{B}^{\prime}\right|}$. Since $1 \geq \frac{\left|\mathrm{B}^{\prime}\right|}{|\mathrm{B}|}=\frac{|\mathrm{B}|-|\mathrm{B} \cap \mathrm{A}|}{|\mathrm{B}|}=1-\mu_{\mathrm{B}}(\mathrm{A})>1-\delta$, we see $r \in\left((1-\delta)^{2}, \frac{(1+\delta)^{2}}{1-\delta}\right)$. In these terms, $\mu_{\mathrm{A} \cup \mathrm{B}}=\mu_{\mathrm{A} \cup \mathrm{B}^{\prime}}=\frac{|\mathrm{A}|}{|\mathrm{A}|+\left|\mathrm{B}^{\prime}\right|} \mu_{\mathrm{A}}+\frac{\left|\mathrm{B}^{\prime}\right|}{|\mathrm{A}|+\left|\mathrm{B}^{\prime}\right|} \mu_{\mathrm{B}^{\prime}}=\left(\frac{1}{1+r^{-1}}\right) \mu_{\mathrm{A}}+\left(\frac{1}{1+r}\right) \mu_{\mathrm{B}^{\prime}}$. Now we can compute $\left\|\mu_{\mathrm{A} \cup \mathrm{B}}-\frac{1}{2}\left(\mu_{\mathrm{A}}+\mu_{\mathrm{B}^{\prime}}\right)\right\|_{1} \leq\left|\frac{1}{2}-\frac{1}{1+r^{-1}}\right| \cdot\left\|\mu_{\mathrm{A}}\right\|_{1}+\left|\frac{1}{2}-\frac{1}{1+r}\right| \cdot\left\|\mu_{\mathrm{B}^{\prime}}\right\|=\left|\frac{1-r}{1+r}\right|<2 \delta$. On the other hand, $\left\|\mu_{\mathrm{B}}-\mu_{\mathrm{B}^{\prime}}\right\|_{1}=2 \frac{\left|\mathrm{B} \backslash \mathrm{B}^{\prime}\right|}{|\mathrm{B}|}<2 \delta$, so $\left\|\frac{1}{2}\left(\mu_{\mathrm{A}}+\mu_{\mathrm{B}^{\prime}}\right)-\frac{1}{2}\left(\mu_{\mathrm{A}}+\mu_{\mathrm{B}}\right)\right\|_{1}<\delta$. The result follows by the triangle inequality.

Lemma 4.4. Suppose $\mathrm{A}, \mathrm{B} \in \mathscr{C}^{+}(\mathrm{K}, \delta)$. Then $\mathrm{A} \cup \mathrm{B} \in \mathscr{C}^{+}(\mathrm{K}, 2 \delta)$. If $\mathrm{A} \cap \mathrm{B}=\varnothing$, then $\mathrm{A} \cup \mathrm{B} \in \mathscr{C}^{+}(\mathrm{K}, \delta)$.

Proof. Pick $x \in \mathrm{K}$. Notice $x(\mathrm{~A} \cup \mathrm{B}) \triangle(\mathrm{A} \cup \mathrm{B}) \subset(x \mathrm{~A} \triangle \mathrm{A}) \cup(x \mathrm{~B} \triangle \mathrm{B})$.

It follows that $\frac{|x(\mathrm{~A} \cup \mathrm{B}) \Delta(\mathrm{A} \cup \mathrm{B})|}{|\mathrm{A} \cup \mathrm{B}|} \leq \frac{|x \mathrm{~A} \Delta \mathrm{A}|}{|\mathrm{A} \cup \mathrm{B}|}+\frac{|x \mathrm{~B} \Delta \mathrm{B}|}{|\mathrm{A} \cup \mathrm{B}|}<\frac{\delta|\mathrm{A}|}{|\mathrm{A} \cup \mathrm{B}|}+\frac{\delta|\mathrm{B}|}{|\mathrm{A} \cup \mathrm{B}|}<2 \delta$.

If $\mathrm{A} \cap \mathrm{B}=\varnothing$, then $|\mathrm{A} \cup \mathrm{B}|=|\mathrm{A}|+|\mathrm{B}|$, hence $\frac{\delta|\mathrm{A}|}{|\mathrm{A} \cup \mathrm{B}|}+\frac{\delta|\mathrm{B}|}{|\mathrm{A} \cup \mathrm{B}|}=\delta$.

Theorem 4.5. Let $G$ be noncompact. Then the following statement implies $\operatorname{TLIM}_{0}(\mathrm{G})=\mathrm{TLIM}(\mathrm{G})$ :

$$
(\forall(p, \mathrm{~K}, \epsilon))(\exists \mathrm{M}>0)\left(\forall \mu \in \operatorname{TLIM}_{0}(\mathrm{G})\right)(\forall \mathcal{P} \text { with } \# \mathcal{P}=p)
$$

$\exists \mathrm{A} \in \mathscr{C}^{+}(\mathrm{K}, \epsilon)$ with $|\mathrm{A}| / \mathrm{M} \in(1-\epsilon, 1+\epsilon)$ and $\mu_{\mathrm{A}} \in \mathcal{N}(\mu, \mathcal{P}, \epsilon)$.

The crux of the statement is that $\mathrm{M}$ is allowed to depend on $(\# \mathcal{P}, \mathrm{K}, \epsilon)$, but not on $\mathcal{P}$ itself.

Proof. Pick $(\mathcal{P}, \mathrm{K}, \epsilon)$ and $\mu, v \in \mathrm{TLIM}_{0}(\mathrm{G})$. Say $\mathcal{P}=\left(\mathrm{E}_{1}, \ldots, \mathrm{E}_{p}\right)$ and $\delta=\epsilon / 4$. By hypothesis, obtain $\mathrm{M}>0$ for

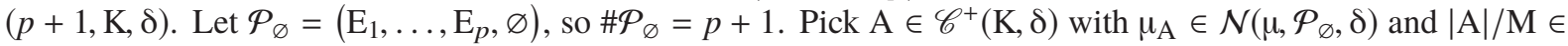
$(1-\delta, 1+\delta)$. Let $\mathcal{P}_{\mathrm{A}}=\left(\mathrm{E}_{1} \backslash \mathrm{A}, \ldots, \mathrm{E}_{p} \backslash \mathrm{A}, \mathrm{A}\right)$. Pick B $\in \mathscr{C}^{+}(\mathrm{K}, \delta)$ with $\mu_{\mathrm{B}} \in \mathcal{N}\left(\nu, \mathcal{P}_{\mathrm{A}}, \delta\right)$ and $|\mathrm{B}| / \mathrm{M} \in(1-\delta, 1+\delta)$. Now $|A| /|B| \in\left((1-\delta)^{2},(1+\delta)^{2}\right)$. Since $A$ is compact but $G$ is not, Lemma 3.3 tells us $v(A)=0$, hence $\mu_{B}(A)<\delta$. Applying Lemma 4.3 to the previous two statements, we conclude $\left\|\frac{1}{2}\left(\mu_{\mathrm{A}}+\mu_{\mathrm{B}}\right)-\mu_{\mathrm{A} \cup \mathrm{B}}\right\|_{1}<3 \delta$. By the triangle inequality, $\mu_{\mathrm{A} \cup \mathrm{B}} \in \mathcal{N}\left(\frac{1}{2}(\mu+v), \mathcal{P}, 4 \delta\right)$. By Lemma 4.4, $\mathrm{A} \cup \mathrm{B} \in \mathscr{C}^{+}(\mathrm{K}, 2 \delta)$. We conclude $\frac{1}{2}(\mu+v) \in \mathrm{TLIM}_{0}(\mathrm{G})$. By Lemma 4.2, we are done. 


\section{ORNSTEIN-WeISS QUASI-TILING}

5.1. We require the following notions of $(\mathrm{K}, \epsilon)$-invariance.

$\mathscr{C}_{0}^{+}(\mathrm{K}, \epsilon)=\{\mathrm{A} \subset \mathrm{G}: \mathrm{A}$ is compact and $(\forall x \in \mathrm{K})|x \mathrm{~A} \triangle \mathrm{A}| /|\mathrm{A}|<\epsilon\}$. This is just $\mathscr{C}^{+}(\mathrm{K}, \epsilon)$ above.

$\mathscr{C}_{1}^{+}(\mathrm{K}, \epsilon)=\{\mathrm{A} \subset \mathrm{G}: \mathrm{A}$ is compact and $|\mathrm{KA} \triangle \mathrm{A}| /|\mathrm{A}|<\epsilon\}$.

$\mathscr{C}_{2}^{+}(\mathrm{K}, \epsilon)=\left\{\mathrm{A} \subset \mathrm{G}: \mathrm{A}\right.$ is compact and $\left.\left|\partial_{\mathrm{K}}(\mathrm{A})\right| /|\mathrm{A}|<\epsilon\right\}$, where $\partial_{\mathrm{K}}(\mathrm{A})=\mathrm{KA} \backslash \bigcap_{x \in \mathrm{K}} x \mathrm{~A}$.

This differs from [OW87], where "the K-boundary of A" is defined as $\mathrm{K}^{-1} \mathrm{~A} \backslash \bigcap_{x \in \mathrm{K}^{-1}} x \mathrm{~A}$.

For $j \in\{0,1,2\}$, define

$$
\operatorname{TLIM}_{j}(\mathrm{G})=\left\{\mu \in \operatorname{TLIM}(\mathrm{G}):(\forall(\mathcal{P}, \mathrm{K}, \epsilon))\left(\exists \mathrm{A} \in \mathscr{C}_{j}^{+}(\mathrm{K}, \epsilon)\right) \mu_{\mathrm{A}} \in \mathcal{N}(\mu, \mathcal{P}, \epsilon)\right\} .
$$

We shall say " $\mathscr{C}_{i}^{+}$is asymptotically contained in $\mathscr{C}_{j}^{+}$" to mean the following:

$$
(\forall(\mathrm{K}, \epsilon))\left(\exists\left(\mathrm{K}^{\prime}, \epsilon^{\prime}\right)\right)\left(\forall \mathrm{A} \in \mathscr{C}_{i}^{+}\left(\mathrm{K}^{\prime}, \epsilon^{\prime}\right)\right) \exists \mathrm{B} \in \mathscr{C}_{j}^{+}(\mathrm{K}, \epsilon) \text { with }\left\|\mu_{\mathrm{A}}-\mu_{\mathrm{B}}\right\|_{1}<\epsilon .
$$

Lemma 5.2. To prove $\operatorname{TLIM}_{i}(\mathrm{G}) \subset \operatorname{TLIM}_{j}(\mathrm{G})$, it suffices to show $\mathscr{C}_{i}^{+}$is asymptotically contained in $\mathscr{C}_{j}^{+}$.

Proof. Pick $(\mathcal{P}, \mathrm{K}, \epsilon)$ and $\mu \in \mathrm{TLIM}_{i}(\mathrm{G})$. By hypothesis, obtain $\left(\mathrm{K}^{\prime}, \epsilon^{\prime}\right)$. Obtain A $\in \mathscr{C}_{i}^{+}\left(\mathrm{K}^{\prime}, \epsilon^{\prime}\right)$ with $\mu_{\mathrm{A}} \in$ $\mathcal{N}(\mu, \mathcal{P}, \epsilon)$. Obtain $\mathrm{B} \in \mathscr{C}_{j}^{+}(\mathrm{K}, \epsilon)$ with $\left\|\mu_{\mathrm{A}}-\mu_{\mathrm{B}}\right\|_{1}<\epsilon$. By the triangle inequality, $\mu_{\mathrm{B}} \in \mathcal{N}(\mu, \mathcal{P}, 2 \epsilon)$. Since $\epsilon$ was arbitrary, we conclude $\mu \in \operatorname{TLIM}_{j}(\mathrm{G})$.

Lemma 5.3. $\operatorname{TLIM}_{0}(\mathrm{G})=\operatorname{TLIM}_{1}(\mathrm{G})=\operatorname{TLIM}_{2}(\mathrm{G})$.

Proof. Trivially, $\mathscr{C}_{2}^{+}(\mathrm{K}, \epsilon) \subset \mathscr{C}_{1}^{+}(\mathrm{K}, \epsilon)$. To prove $\mathscr{C}_{1}^{+}(\mathrm{K}, \epsilon) \subset \mathscr{C}_{0}^{+}(\mathrm{K}, 2 \epsilon)$, suppose $x \in \mathrm{K}$ and A $\in \mathscr{C}_{1}^{+}(\mathrm{K}, \epsilon)$. Then $|x \mathrm{~A} \triangle \mathrm{A}|=2|x \mathrm{~A} \backslash \mathrm{A}| \leq 2|\mathrm{KA} \backslash \mathrm{A}|<2 \epsilon|\mathrm{A}|$. [Eme68, Theorem 15] shows that $\mathscr{C}_{0}^{+}$is asymptotically contained in $\mathscr{C}_{1}^{+}$. To prove $\mathscr{C}_{1}^{+}$is asymptotically contained in $\mathscr{C}_{2}^{+}$, pick $(\mathrm{K}, \epsilon)$ and let $\mathrm{J}=\mathrm{K} \cup \mathrm{K}^{-1} \cup\{e\}$. Suppose $\mathrm{A} \in \mathscr{C}_{1}^{+}\left(\mathrm{J}^{2}, \epsilon\right)$, and let $\mathrm{B}=\mathrm{JA}$. Then $\mathrm{A} \subset \partial_{\mathrm{J}}(\mathrm{B})$, and $\mathrm{JB} \backslash \partial_{\mathrm{J}}(\mathrm{B}) \subset \mathrm{J}^{2} \mathrm{~A} \backslash \mathrm{A}$, which shows $\mathrm{B} \in \mathscr{C}_{2}^{+}(\mathrm{J}, \epsilon) \subset \mathscr{C}_{2}^{+}(\mathrm{K}, \epsilon)$. Also, since $\mathrm{B} \subset \mathrm{J}^{2} \mathrm{~A}$, we see $|\mathrm{B}|<(1+\epsilon)|\mathrm{A}|$, hence $\left\|\mu_{\mathrm{A}}-\mu_{\mathrm{B}}\right\|_{1}=2 \frac{|\mathrm{A}| \mathrm{B} \mid}{|\mathrm{A}|}<2 \epsilon$.

Lemma 5.4. Suppose $\mathrm{G}$ is noncompact, and pick $(\mathcal{P}, \mathrm{K}, \epsilon)$ and $\mu \in \operatorname{TLIM}_{0}(\mathrm{G})$. There exists a family of mutually disjoint sets $\left\{\mathrm{B}_{n}: n \in \mathbb{N}\right\} \subset \mathscr{C}_{1}^{+}(\mathrm{K}, \epsilon)$ with $\left\{\mu_{\mathrm{B}_{n}}: n \in \mathbb{N}\right\} \subset \mathcal{N}(\mu, \mathcal{P}, \epsilon)$.

Proof. By [Eme68, Theorem 15], obtain $\left(\mathrm{K}^{\prime}, \epsilon^{\prime}\right)$ so for each A $\in \mathscr{C}_{0}^{+}\left(\mathrm{K}^{\prime}, \epsilon^{\prime}\right)$, there exists B $\in \mathscr{C}_{1}^{+}(\mathrm{K}, \epsilon)$ with $\left\|\mu_{\mathrm{A}}-\mu_{\mathrm{B}}\right\|_{1}<\epsilon / 2$. By Lemma 3.5, choose a family of mutually disjoint sets $\left\{\mathrm{A}_{n}: n \in \mathbb{N}\right\} \subset \mathscr{C}_{0}^{+}\left(\mathrm{K}^{\prime}, \epsilon^{\prime}\right)$ with $\left\{\mu_{\mathrm{A}_{n}}: n \in \mathbb{N}\right\} \subset \mathcal{N}(\mu, \mathcal{P}, \epsilon / 2)$. For each $n$, choose $\mathrm{B}_{n} \in \mathscr{C}_{1}^{+}(\mathrm{K}, \epsilon)$ with $\left\|\mu_{\mathrm{A}_{n}}-\mu_{\mathrm{B}_{n}}\right\|_{1}<\epsilon / 2$. By the triangle inequality, $\mu_{\mathrm{B}_{n}} \in \mathcal{N}(\mu, \mathcal{P}, \epsilon)$.

Lemma 5.5. Suppose $G$ is noncompact unimodular. Pick $(\mathcal{P}, K, \epsilon), \mu \in \operatorname{TLIM}_{0}(G)$, and $M>0$. Then there exists $\mathrm{B} \in \mathscr{C}_{2}^{+}(\mathrm{K}, \epsilon)$ with $|\mathrm{B}| \geq \mathrm{M}$ and $\mu_{\mathrm{B}} \in \mathcal{N}(\mu, \mathcal{P}, \epsilon)$.

Proof. Without loss of generality, assume $|\mathrm{K}|>0$. Let $\delta=\epsilon / 3$. By Lemma 5.4, choose disjoint sets $\left\{\mathrm{A}_{n}: n \in \mathbb{N}\right\} \subset$ $\mathscr{C}_{1}^{+}\left(\mathrm{K}^{2}, \epsilon\right)$ with $\left\{\mu_{\mathrm{A}_{n}}: n \in \mathbb{N}\right\} \subset \mathcal{N}(\mu, \mathcal{P}, \delta)$. For each $n,\left|\mathrm{~A}_{n}\right|>(1-\epsilon)\left|\mathrm{K}^{2} \mathrm{~A}_{n}\right|>\left|\mathrm{K}^{2}\right|$, where the second inequality holds because $\mathrm{G}$ is unimodular. For sufficiently large $m,\left|\mathrm{~A}_{1} \cup \ldots \cup \mathrm{A}_{m}\right| \geq \mathrm{M}$. Define $\mathrm{A}=\mathrm{A}_{1} \cup \ldots \cup \mathrm{A}_{m}$. Since this union is disjoint, it is easy to check $A \in \mathscr{C}_{1}^{+}\left(\mathrm{K}^{2}, \epsilon\right)$. Notice $\mu_{\mathrm{A}}=\frac{\left|\mathrm{A}_{1}\right|}{|\mathrm{A}|} \mu_{\mathrm{A}_{1}}+\ldots+\frac{\left|\mathrm{A}_{m}\right|}{|\mathrm{A}|} \mu_{\mathrm{A}_{m}} \in \mathcal{N}(\mu, \mathcal{P}, \delta)$, as the latter set is convex. Finally, let $\mathrm{B}=\mathrm{KA}$. It follows, as in the proof of Lemma 5.3, that $\mathrm{B} \in \mathscr{C}_{2}^{+}(\mathrm{K}, \epsilon)$ and $\left\|\mu_{\mathrm{A}}-\mu_{\mathrm{B}}\right\|_{1}<2 \delta$, hence $\mu_{\mathrm{B}} \in \mathcal{N}(\mu, \mathcal{P}, 3 \delta)$ by the triangle inequality.

Recall that $\sqcup$ denotes a disjoint union.

Definition 5.6. Let $A \subset G$ and $T_{1} \subset \ldots \subset T_{n} \subset \mathrm{G}$ have finite positive measure. $\mathcal{T}=\left\{\mathrm{T}_{1}, \ldots, \mathrm{T}_{n}\right\}$ is said to $\boldsymbol{\epsilon}$-quasi-tile $\mathbf{A}$ if there exists $\mathrm{R}=\mathrm{S}_{1} \cup \ldots \cup \mathrm{S}_{\mathrm{N}}=\mathrm{R}_{1} \sqcup \ldots \sqcup \mathrm{R}_{\mathrm{N}}$ satisfying the following:

(1) For $i \in\{1, \ldots, \mathrm{N}\}, \mathrm{S}_{i}=\mathrm{T} x$ for some $\mathrm{T} \in \mathcal{T}$ and $x \in \mathrm{G}$.

(2) For $i \in\{1, \ldots, \mathrm{N}\}, \mathrm{R}_{i} \subset \mathrm{S}_{i}$ with $\left\|\mu_{\mathrm{R}_{i}}-\mu_{\mathrm{S}_{i}}\right\|_{1}<\epsilon$.

(3) $\left\|\mu_{\mathrm{A}}-\mu_{\mathrm{R}}\right\|_{1}<\epsilon$.

[OW87] gives the following weaker conditions in place of (2) and (3):

$\left(2^{\prime}\right)$ For $i \in\{1, \ldots, \mathrm{N}\}, \mathrm{R}_{i} \subset \mathrm{S}_{i}$ with $\left|\mathrm{R}_{i}\right|>(1-\epsilon)\left|\mathrm{S}_{i}\right|$.

$\left(3^{\prime}\right) \mathrm{R} \subset \mathrm{A}$ with $|\mathrm{R}|>(1-\epsilon)|\mathrm{A}|$.

Of course (2') implies $\left\|\mu_{\mathrm{S}_{i}}-\mu_{\mathrm{R}_{i}}\right\|_{1}=2 \frac{\left|\mathrm{S}_{i} \backslash \mathrm{R}_{i}\right|}{\left|\mathrm{S}_{i}\right|}<2 \epsilon$, and (3') implies $\left\|\mu_{\mathrm{A}}-\mu_{\mathrm{R}}\right\|_{1}=2 \frac{|\mathrm{A} \backslash \mathrm{R}|}{|\mathrm{A}|}<2 \epsilon$. Therefore the two definitions become equivalent when we quantify over all $\epsilon \in(0,1)$, as in Lemma 5.7. 
Lemma 5.7. Let $\mathrm{G}$ be unimodular. Pick $(\mathrm{K}, \epsilon)$. Then there exists $\epsilon^{\prime}>0$ and $\mathcal{T}=\left\{\mathrm{T}_{1}, \ldots, \mathrm{T}_{n}\right\} \subset \mathscr{C}_{2}^{+}(\mathrm{K}, \epsilon)$ such that $\mathcal{T} \epsilon$-quasi-tiles any $\mathrm{A} \in \mathscr{C}_{2}^{+}\left(\mathrm{T}_{n}^{-1} \mathrm{~T}_{n}, \epsilon^{\prime}\right)$.

Proof. This is [OW87, p. 30, Theorem 3 and Remark], although Ornstein and Weiss write $\left\{\mathrm{F}_{1}, \ldots, \mathrm{F}_{\mathrm{K}}\right\}$ instead of $\left\{\mathrm{T}_{1}, \ldots, \mathrm{T}_{n}\right\}$, and invert the definition of $\partial_{\mathrm{K}}(\mathrm{A})$ as described in 5.1.

Lemma 5.8. If $S_{i} \in \mathscr{C}_{1}^{+}(\mathrm{K}, \epsilon)$ and $\mathrm{R}_{i} \subset \mathrm{S}_{i}$ with $\left\|\mu_{\mathrm{R}_{i}}-\mu_{S_{i}}\right\|_{1}<\epsilon$, then $\mathrm{R}_{i} \in \mathscr{C}_{1}^{+}(\mathrm{K}, 3 \epsilon)$.

Proof. $\frac{\left|\mathrm{KR}_{i} \backslash \mathrm{R}_{i}\right|}{\left|\mathrm{R}_{i}\right|} \leq \frac{\left|\mathrm{S}_{i}\right|}{\left|\mathrm{R}_{i}\right|} \cdot \frac{\left|\mathrm{KS}_{i} \backslash \mathrm{S}_{i}\right|}{\left|\mathrm{S}_{i}\right|}+\frac{\left|\mathrm{S}_{i} \backslash \mathrm{R}_{i}\right|}{\left|\mathrm{R}_{i}\right|}<(1+\epsilon) \cdot \epsilon+\left\|\mu_{\mathrm{R}_{i}}-\mu_{\mathrm{S}_{i}}\right\|_{1}<3 \epsilon$.

Theorem 5.9. If $\mathrm{G}$ is noncompact unimodular, $\operatorname{TLIM}_{0}(\mathrm{G})=\operatorname{TLIM}(\mathrm{G})$.

Proof. Pick $(\mathcal{P}, \mathrm{K}, \epsilon)$ and $\mu \in \mathrm{TLIM}_{0}(\mathrm{G})$, say $\mathcal{P}=\left\{\mathrm{E}_{1}, \ldots, \mathrm{E}_{p}\right\}$. Let $\mathrm{V}=\left\{x \in \mathbb{R}^{p}:\|x\|_{1}=1\right\}$. For $m \in \mathcal{M}(\mathrm{G})$, let $v(m)=\left[\begin{array}{lll}m\left(\mathrm{E}_{1}\right) & \ldots & m\left(\mathrm{E}_{p}\right)\end{array}\right] \in \mathrm{V}$. Thus $m \in \mathcal{N}(\mu, \mathcal{P}, \epsilon)$ iff $\|v(m)-v(\mu)\|_{\infty}<\epsilon$. Let $\mathrm{D} \subset \mathrm{V}$ be a finite $\epsilon$-dense subset, i.e. for each $v \in \mathrm{V}$ there exists $d \in \mathrm{D}$ with $\|v-d\|_{\infty}<\epsilon$. By Lemma 5.7, obtain $\mathcal{T}=\left\{\mathrm{T}_{1}, \ldots, \mathrm{T}_{n}\right\} \subset \mathscr{C}_{2}^{+}(\mathrm{K}, \epsilon)$ and $\epsilon^{\prime}>0$. Let $\mathrm{M}=\# \mathrm{D} \cdot\left|\mathrm{T}_{n}\right| \cdot \epsilon^{-1}$. Notice that $\mathrm{M}$ depends only on $(p, \mathrm{~K}, \epsilon)$. By Lemma 5.5, pick B $\in \mathscr{C}_{2}^{+}\left(\mathrm{T}_{n}^{-1} \mathrm{~T}_{n}, \epsilon^{\prime}\right)$ with $|\mathrm{B}| \geq \mathrm{M}$ and $\mu_{\mathrm{B}} \in \mathcal{N}(\mu, \mathcal{P}, \epsilon)$. The goal is to construct $\mathrm{A} \subset \mathrm{B}$ such that $\mathrm{A} \in \mathscr{C}_{1}^{+}(\mathrm{K}, 3 \epsilon),|\mathrm{A}| / \mathrm{M} \in(1-\epsilon, 1]$, and $\left\|v\left(\mu_{\mathrm{A}}\right)-v\left(\mu_{\mathrm{B}}\right)\right\|_{\infty}<5 \epsilon$. This implies $\mu_{\mathrm{A}} \in \mathcal{N}(\mu, \mathcal{P}, 6 \epsilon)$. Since $\epsilon$ was arbitrary, $\operatorname{TLIM}_{0}(\mathrm{G})=\operatorname{TLIM}(\mathrm{G})$ will follow by Theorem 4.5 .

As in Definition 5.6, let $\mathrm{R}=\bigsqcup_{i=1}^{\mathrm{N}} \mathrm{R}_{i}$ with $\left\|\mu_{\mathrm{A}}-\mu_{\mathrm{R}}\right\|_{1}<\epsilon$. Clearly $\left\|v\left(\mu_{\mathrm{A}}\right)-v\left(\mu_{\mathrm{R}}\right)\right\|_{\infty}<\epsilon$. By Lemma 5.8, each $\mathrm{R}_{i}$ is in $\mathscr{C}_{1}^{+}(\mathrm{K}, 3 \epsilon)$. Since they are disjoint, any union of them is in $\mathscr{C}_{1}^{+}(\mathrm{K}, 3 \epsilon)$ as well. The crucial detail is that each $\left|\mathrm{R}_{i}\right|$ is at most $\left|\mathrm{T}_{n}\right|$. Let $r_{i}=\left|\mathrm{R}_{i}\right| /|\mathrm{R}|$, so $\sum r_{i}=1$ and $\mu_{\mathrm{R}}=\sum r_{i} \cdot \mu_{\mathrm{R}_{i}}$.

For each $\mathrm{R}_{i}$, pick $d_{i} \in \mathrm{D}$ with $\left\|d_{i}-v\left(\mu_{\mathrm{R}_{i}}\right)\right\|_{\infty}<\epsilon$. For each $d \in \mathrm{D}$, let $\mathrm{C}_{d}=\left\{i: d_{i}=d\right\}$ and $c_{d}=\sum\left\{r_{i}: d_{i}=d\right\}$. Thus $\left\|v\left(\mu_{\mathrm{R}}\right)-\sum_{d \in \mathrm{D}} c_{d} \cdot d\right\|_{\infty}<\epsilon$. Let $\mathrm{S}_{d} \subset \mathrm{C}_{d}$ be a maximal subset such that $s_{d}=\sum\left\{r_{i}: i \in \mathrm{S}_{d}\right\} \leq \frac{\mathrm{M}}{|\mathrm{R}|} c_{d}$.

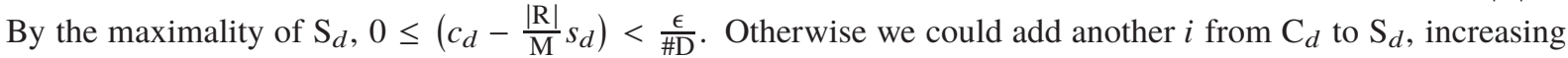
$\frac{|\mathrm{R}|}{\mathrm{M}} s_{d}$ by $\frac{|\mathrm{R}|}{\mathrm{M}} r_{i}=\frac{\left|\mathrm{R}_{i}\right|}{\mathrm{M}} \leq \frac{\left|\mathrm{T}_{n}\right|}{\mathrm{M}}=\frac{\epsilon}{\# \mathrm{D}}$. Let $\mathrm{A}=\bigcup_{d \in \mathrm{D}} \bigcup_{i \in \mathrm{S}_{d}} \mathrm{R}_{i}$, so that $\mu_{\mathrm{A}}=\sum_{d \in \mathrm{D}} \sum_{i \in \mathrm{S}} \frac{|\mathrm{R}|}{|\mathrm{A}|} r_{i} \cdot \mu_{\mathrm{R}_{i}}$. Notice $\frac{|\mathrm{A}|}{\mathrm{M}}=\sum_{d \in \mathrm{D}} \sum_{i \in \mathrm{S}_{d}} \frac{|\mathrm{R}|}{\mathrm{M}} \frac{\left|\mathrm{R}_{i}\right|}{|\mathrm{R}|}=\sum_{d \in \mathrm{D}} \frac{|\mathrm{R}|}{\mathrm{M}} s_{d} \in(1-\epsilon, 1]$. Finally, we apply the triangle inequality: $\| v\left(\mu_{\mathrm{B}}\right)-$ $v\left(\mu_{\mathrm{A}}\right)\left\|_{\infty} \leq\right\| v\left(\mu_{\mathrm{B}}\right)-v\left(\mu_{\mathrm{R}}\right)\left\|_{\infty}+\right\| v\left(\mu_{\mathrm{R}}\right)-\sum_{d \in \mathrm{D}} c_{d} \cdot d\left\|_{\infty}+\right\| \sum_{d \in \mathrm{D}}\left(c_{d}-\frac{|\mathrm{R}|}{\mathrm{M}} s_{d}\right) \cdot d\left\|_{\infty}+\right\| \sum_{d \in \mathrm{D}}\left(\frac{|\mathrm{R}|}{\mathrm{M}}-\frac{|\mathrm{R}|}{|\mathrm{A}|}\right) s_{d} \cdot d \|_{\infty}+$ $\left\|\sum_{d \in \mathrm{D}} \sum_{i \in \mathrm{S}_{d}} \frac{|\mathrm{R}|}{|\mathrm{A}|} r_{i} \cdot\left(d-v\left(\mu_{\mathrm{R}_{i}}\right)\right)\right\|_{\infty}<5 \epsilon$.

\section{EAsy CASES}

Theorem 6.1. If $\kappa(\mathrm{G})>\mathbb{N}$, $\operatorname{TLIM}_{0}(\mathrm{G})=\operatorname{TLIM}(\mathrm{G})$.

Proof. Pick $\mu, v \in \mathrm{TLIM}_{0}(\mathrm{G})$ and $(\mathcal{P}, \mathrm{K}, \epsilon)$. By the same technique as in Lemma 3.5, obtain mutually disjoint sets $\left\{\mathrm{A}_{\alpha}, \mathrm{B}_{\alpha}: \alpha<\kappa(\mathrm{G})\right\} \subset \mathscr{C}^{+}(\mathrm{K}, \epsilon)$, such that $\mu_{\mathrm{A}_{\alpha}} \in \mathcal{N}(\mu, \mathcal{P}, \epsilon)$, and $\mu_{\mathrm{B}_{\alpha}} \in \mathcal{N}(\nu, \mathcal{P}, \epsilon)$ for each $\alpha$.

Let $r=(1+\epsilon)^{1 / 2}$, and let $\mathrm{I}_{n}=\left[r^{n}, r^{n+1}\right)$ for $n \in \mathbb{Z}$. By the pigeonhole principle, there exist $m, n \in \mathbb{Z}$ such that $\left\{\alpha:\left|\mathrm{A}_{\alpha}\right| \in \mathrm{I}_{m}\right\}$ and $\left\{\alpha:\left|\mathrm{B}_{\alpha}\right| \in \mathrm{I}_{m}\right\}$ are infinite. Pick $\mathrm{M}, \mathrm{N} \in \mathbb{N}$ so that $\mathrm{M} / \mathrm{N} \in \mathrm{I}_{m-n}$. Pick $\mathrm{A}_{1}, \ldots, \mathrm{A}_{\mathrm{N}}$ from $\left\{\mathrm{A}_{\alpha}:\left|\mathrm{A}_{\alpha}\right| \in \mathrm{I}_{m}\right\}$ and $\mathrm{B}_{1}, \ldots, \mathrm{B}_{\mathrm{M}}$ from $\left\{\mathrm{B}_{\alpha}:\left|\mathrm{B}_{\alpha}\right| \in \mathrm{I}_{n}\right\}$. Let $\mathrm{A}=\mathrm{A}_{1} \cup \ldots \cup \mathrm{A}_{\mathrm{N}}$ and $\mathrm{B}=\mathrm{B}_{1} \cup \ldots \cup \mathrm{B}_{\mathrm{M}}$. Thus $|\mathrm{A}| /|\mathrm{B}| \in(1-\epsilon, 1+\epsilon)$. Since the $\mathrm{A}_{i}$ 's and $\mathrm{B}_{i}$ 's are mutually disjoint, we have $\mathrm{A}, \mathrm{B}, \mathrm{A} \cup \mathrm{B} \in \mathscr{C}^{+}(\mathrm{K}, \epsilon)$. Clearly $\mu_{\mathrm{A}} \in \mathcal{N}(\mu, \mathcal{P}, \epsilon)$ and $\mu_{\mathrm{B}} \in \mathcal{N}(\nu, \mathcal{P}, \epsilon)$. By Lemma 4.3 and the triangle inequality, $\mu_{\mathrm{A} \cup \mathrm{B}} \in \mathcal{N}\left(\frac{1}{2}(\mu+v), \mathcal{P}, 4 \epsilon\right)$. Since $\epsilon$ was arbitrary, we conclude $\frac{1}{2}(\mu+v) \in \operatorname{TLIM}_{0}(\mathrm{G})$.

Theorem 6.2. If $\mathrm{G}$ is $\sigma$-compact non-unimodular, $\operatorname{TLIM}_{0}(\mathrm{G}) \neq \operatorname{TLIM}(\mathrm{G})$.

Proof. Recall that the modular function $\Delta$ is defined by $|\mathrm{E} x|=|\mathrm{E}| \Delta(x)$.

Let $\mathrm{K}_{1} \subset \mathrm{K}_{2} \subset \ldots$ be a sequence of compacta with $\bigcup_{n} \mathrm{~K}_{n}=\mathrm{G}$. For each $n$, pick $\mathrm{F}_{n} \in \mathscr{C}^{+}\left(\mathrm{K}_{n}, \frac{1}{n}\right)$, then pick $x_{n}, y_{n} \in \mathrm{G}$ such that $\mathrm{F}_{n} x_{n} \subset\{x: \Delta(x) \geq 1\}$ and $\mathrm{F}_{n} y_{n} \subset\left\{x: \Delta(x) \leq \min \left(1,\left|\mathrm{~F}_{n}\right|^{-1} 2^{-n}\right)\right\}$. Let $\mathrm{X}=\bigcup_{n} \mathrm{~F}_{n} x_{n}$ and $\mathrm{Y}=\cup_{n} \mathrm{~F}_{n} y_{n}$. By construction, $\mathrm{X} \cap \mathrm{Y}=\varnothing$ and $|\mathrm{Y}| \leq 1$. Let $\mu$ be an accumulation point of $\left\langle\mu_{\mathrm{F}_{n} x_{n}}\right\rangle_{n=1}^{\infty}$ and $v$ an accumulation point of $\left\langle\mu_{\mathrm{F}_{n} y_{n}}\right\rangle_{n=1}^{\infty}$. Thus $\mu, v \in \operatorname{TLIM}_{0}(\mathrm{G})$. Let $m=\frac{1}{2}(\mu+v)$. Notice $\mu(\mathrm{X})=v(\mathrm{Y})=1$ and $\mu(\mathrm{Y})=v(\mathrm{X})=0$, hence $m(\mathrm{X})=m(\mathrm{Y})=\frac{1}{2}$.

Suppose $m \in \operatorname{TLIM}_{0}(\mathrm{G})$. Let $\mathrm{K}$ be any compact set with $|\mathrm{K}| \geq \frac{7}{2}$. Define $\epsilon=\frac{1}{6}$ and $\mathcal{P}=\{\mathrm{X}, \mathrm{Y}\}$. Pick $\mathrm{A} \in \mathscr{C}_{1}^{+}(\mathrm{K}, \epsilon)$ with $\mu_{\mathrm{A}} \in \mathcal{N}(m, \mathcal{P}, \epsilon)$. Now $\frac{1}{|\mathrm{~A}|} \geq \frac{|\mathrm{Y}|}{|\mathrm{A}|} \geq \frac{|\mathrm{Y} \cap \mathrm{A}|}{|\mathrm{A}|}=\mu_{\mathrm{A}}(\mathrm{Y})>m(\mathrm{Y})-\epsilon=\frac{1}{3}$, so $|\mathrm{A}|<3$. On the other 
hand, $\mu_{\mathrm{A}}(\mathrm{X})>\frac{1}{3}$, so $|\mathrm{A} \cap \mathrm{X}| \neq 0$. Say $a \in \mathrm{A} \cap \mathrm{X}$. Now $\frac{7}{2} \leq|\mathrm{K}| \leq|\mathrm{K} a| \leq|\mathrm{KA}| \leq|\mathrm{A}|+|\mathrm{KA} \backslash \mathrm{A}|<(1+\epsilon)|\mathrm{A}|$, so $3<|\mathrm{A}|$, a contradiction. Hence $m \in \operatorname{TLIM}(\mathrm{G}) \backslash \operatorname{TLIM}_{0}(\mathrm{G})$.

\section{NON-TOPOLOGICAL INVARIANT MEANS}

In this section, triples of the form $(\mathcal{P}, \mathrm{K}, \epsilon)$ range over finite measurable partitions $\mathcal{P}$ of $\mathrm{G}$, finite sets $\mathrm{K} \subset \mathrm{G}$, and $\epsilon \in(0,1)$. In these terms, we define

$$
\operatorname{LIM}_{0}(\mathrm{G})=\left\{\mu \in \operatorname{LIM}(\mathrm{G}):(\forall(\mathcal{P}, \mathrm{K}, \epsilon))\left(\exists \mathrm{A} \in \mathscr{C}^{+}(\mathrm{K}, \epsilon)\right) \mu_{\mathrm{A}} \in \mathcal{N}(\mu, \mathcal{P}, \epsilon)\right\}
$$

Lemma 7.1 ([HS09, Theorem 2.12]). The closed convex hull of $\operatorname{LIM}_{0}(\mathrm{G})$ is all of $\operatorname{LIM}(\mathrm{G})$.

Theorem 7.2. If $\kappa(G)>\mathbb{N}$, then $\operatorname{LIM}_{0}(\mathrm{G})=\operatorname{LIM}(\mathrm{G})$.

Proof. The proof is identical to that of Theorem 6.1, but with Lemma 7.1 in place of Lemma 4.1.

7.3. Fix a finite measurable partition $\mathcal{P}=\left\{\mathrm{E}_{1}, \ldots, \mathrm{E}_{p}\right\}$, and a finite set $\mathrm{X}=\left\{x_{1}, \ldots, x_{n}\right\}$, with $x_{1}=e$. For $\mathrm{C}=\left(c_{1}, \ldots, c_{n}\right) \in\{1, \ldots, p\}^{n}$, define $\mathrm{E}(\mathrm{C})=\left\{y \in \mathrm{G}: x_{1} y \in \mathrm{E}_{c_{1}}, \ldots, x_{n} y \in \mathrm{E}_{c_{n}}\right\}=\bigcap_{k=1}^{n} x_{k}^{-1} \mathrm{E}_{c_{k}}$. Thus $Q=$ $\left\{\mathrm{E}(\mathrm{C}): \mathrm{C} \in\{1, \ldots, p\}^{n}\right\}$ is a refinement of $\mathcal{P}$. Notice $\mathrm{E}_{i}=\bigcup\left\{\mathrm{E}(\mathrm{C}): c_{1}=i\right\}$ and $x_{k}^{-1} \mathrm{E}_{i}=\bigcup\left\{\mathrm{E}(\mathrm{C}): c_{k}=i\right\}$.

The idea of refining $\mathcal{P}$ this way is due to [RW01].

Theorem 7.4. If $G$ is non-discrete but amenable-as-discrete, then $\operatorname{LIM}_{0}(G)=\operatorname{LIM}(G)$.

Proof. Pick $(\mathcal{P}, \mathrm{K}, \epsilon)$ and $\mu \in \operatorname{LIM}(\mathrm{G})$. Let $\mathrm{X}=\left\{x_{1}, \ldots, x_{n}\right\}$ be $(\mathrm{K}, \epsilon)$-invariant, with $x_{1}=e$. Let $Q$ refine $\mathcal{P}$ as in 7.3, and let $\left\{\mathrm{F}_{1}, \ldots, \mathrm{F}_{q}\right\}=\{\mathrm{F} \in Q:|\mathrm{F}|>0\}$. Let $m=\min \left\{1,\left|\mathrm{~F}_{1}\right|, \ldots,\left|\mathrm{F}_{q}\right|\right\}$ and $c=m /\left(n^{2} q\right)$. By Lemma 2.5, pick $\mathrm{S}_{1} \subset \mathrm{F}_{1}$ such that $0<\left|\mathrm{S}_{1}\right| \leq c$ and $\mathrm{S}_{1} \mathrm{~S}_{1}^{-1} \cap \mathrm{X}^{-1} \mathrm{X}=\{e\}$. For $k<q$, inductively choose $\mathrm{S}_{k+1} \subset \mathrm{F}_{k+1} \backslash \mathrm{X}^{-1} \mathrm{X}\left(\mathrm{S}_{1} \cup \ldots \cup \mathrm{S}_{k}\right)$ with $0<\left|\mathrm{S}_{k+1}\right| \leq c$ and $\mathrm{S}_{k+1} \mathrm{~S}_{k+1}^{-1} \cap \mathrm{X}^{-1} \mathrm{X}=\{e\}$. This is possible, since $\left|\mathrm{F}_{k+1} \backslash \mathrm{X}^{-1} \mathrm{X}\left(\mathrm{S}_{1} \cup \ldots \cup \mathrm{S}_{k}\right)\right| \geq m-n^{2} k c>0$.

Now let $m^{\prime}=\min \left\{\left|\mathrm{S}_{1}\right|,\left|\mathrm{S}_{2}\right|, \ldots,\left|\mathrm{S}_{q}\right|\right\}$. For each $i$, choose $\mathrm{S}_{i}^{\prime} \subset \mathrm{S}_{i}$ with $\left|\mathrm{S}_{i}^{\prime}\right|=m^{\prime} \cdot \mu\left(\mathrm{E}_{i}\right)$, then let $\mathrm{S}=$ $\mathrm{S}_{1}^{\prime} \cup \ldots \cup \mathrm{S}_{q}^{\prime}$. By construction, $\mathrm{XS}=x_{1} \mathrm{~S} \sqcup \ldots \sqcup x_{n} \mathrm{~S}$. For $y \in \mathrm{K},|y \mathrm{XS} \triangle \mathrm{XS}| /|\mathrm{XS}|=\#(y \mathrm{X} \triangle \mathrm{X}) / \#(\mathrm{X})<\epsilon$, hence $\mathrm{XS} \in \mathscr{C}^{+}(\mathrm{K}, \epsilon)$. Notice $\mu_{\mathrm{XS}}=\frac{1}{n} \sum_{k=1}^{n} \mu_{x_{k} \mathrm{~S}}$. For each $i$ and $k, \mu_{x_{k} \mathrm{~S}}\left(\mathrm{E}_{i}\right)=\mu_{\mathrm{S}}\left(x_{k}^{-1} \mathrm{E}_{i}\right)=\sum\left\{\mu_{\mathrm{S}}(\mathrm{E}(\mathrm{C})): c_{k}=i\right\}=$ $\sum\left\{\mu(\mathrm{E}(\mathrm{C})): c_{k}=i\right\}=\mu\left(x_{k}^{-1} \mathrm{E}_{i}\right)=\mu\left(\mathrm{E}_{i}\right)$. Hence $\mu_{\mathrm{XS}}\left(\mathrm{E}_{i}\right)=\mu\left(\mathrm{E}_{i}\right)$.

\section{REFERENCES}

[Cho70] Ching Chou. On topologically invariant means on a locally compact group. Trans. Amer. Math. Soc., 151(2):443-456, 1970.

[Eme68] William R. Emerson. Ratio properties in locally compact amenable groups. Trans. Amer. Math. Soc., 133(1):179-204, 1968.

[Gre69] Frederick P. Greenleaf. Invariant Means on Topological Groups and Their Applications. Van Nostrand, 1969.

[Hop20] John Hopfensperger. Counting topologically invariant means on $\mathrm{L}_{\infty}(\mathrm{G})$ and VN(G) with ultrafilters. Rocky Mt. J. Math., 2020. Advance publication.

[HS09] Neil Hindman and Dona Strauss. Density and invariant means in left amenable semigroups. Topol. Its Appl., 156:2614-2628, 2009.

[Mil81] Paul Milnes. Amenable groups for which every topologically left invariant mean is right invariant. Rocky Mt. J. Math., 1(2):261-266, 1981.

[OW87] Donald S. Ornstein and Benjamin Weiss. Entropy and isomorphism theorems for actions of amenable groups. J. Anal. Math., 48(1):1-141, Dec 1987.

[Ros76] J. Rosenblatt. Invariant Means for the Bounded Measurable Functions on a Non-discrete Locally Compact Group. Math. Ann., 220:219-228, 1976.

[RW01] Joseph M. Rosenblatt and George A. Willis. Weak convergence is not strong convergence for amenable groups. Canad. Math. Bull., 44(2):231-241, 2001.

Department of Mathematics, University at Buffalo, Buffalo, NY 14260-2900, USA

E-mail address: johnhopf@buffalo.edu 